\title{
Enhancement of chlorine on Pd catalyst for H2O2 in-situ synthesis in electro-Fenton system: Kinetics and Mechanism
}

\author{
Linhui Lu ${ }^{1}$, Qingli Shu ${ }^{1}$, Guiru Zhang ${ }^{2}$, Qi Zhang ${ }^{1}$, Ping $\mathrm{Du}^{3}$, and Xuedong Zhu ${ }^{4}$ \\ ${ }^{1}$ East China University of Science and Technology \\ ${ }^{2}$ Shanghai Jiao Tong University \\ ${ }^{3}$ Chinese Research Academy of Environmental Sciences \\ ${ }^{4}$ Affiliation not available
}

October 28, 2021

\begin{abstract}
Palladium-based catalyst has been widely employed in electro-Fenton process for in-situ generation of H2O2. However, the selectivity to $\mathrm{H} 2 \mathrm{O} 2$ achieved so far is still far below application level. In this work, a series of $\mathrm{Cl}-\mathrm{FePd} / \gamma-\mathrm{Al} 2 \mathrm{O} 3 / \mathrm{Al}$ catalysts were prepared by a three-step-impregnation method, exhibiting excellent activity in $\mathrm{H} 2 \mathrm{O} 2$ in-situ synthesis and high efficiency in phenol degradation. The characterization results showed that the $\mathrm{Cl}$ could assist in increasing the content of $\mathrm{Pd} 0$ and reducing the isoelectric point of catalyst, leading to the dramatic promotion in synthesis of $\mathrm{H} 2 \mathrm{O} 2$. Moreover, theoretical calculation and kinetics further demonstrated that the $\mathrm{Cl}$ doping could facilitate the main reaction in $\mathrm{H} 2 \mathrm{O} 2$ synthesis, as well as inhibit side reactions, including the dissociation of $\mathrm{O}-\mathrm{O}$ bond, hydrogenation and decomposition. Furthermore, plausible mechanism and degradation pathways were elaborated based on ESR and GC-MS results. These findings illustrate the value of palladium-based $\mathrm{Cl}-\mathrm{FePd} / \gamma-\mathrm{Al} 2 \mathrm{O} 3 / \mathrm{Al}$ catalyst in its application in electro-Fenton process.
\end{abstract}

\section{Hosted file}

Main Document.docx available at https://authorea.com/users/443465/articles/543462enhancement-of-chlorine-on-pd-catalyst-for-h2o2-in-situ-synthesis-in-electro-fentonsystem-kinetics-and-mechanism 